\title{
Evaluation of methods to adjust for treatment switching in clinical trials
}

\author{
Richard Fox ${ }^{1 *}$, Lucinda Billingham ${ }^{1,2}$, Keith Abrams ${ }^{3}$ \\ From Clinical Trials Methodology Conference 2011 \\ Bristol, UK. 4-5 October 2011
}

\section{Introduction}

Treatment switching in clinical trials dilutes estimates of treatment effect which is problematic in decision making, especially in an economic context. In one example $75 \%$ of patients crossover from the randomised treatment which emphasises the need to address such bias. We consider methodologies that compensate for this bias.

\section{Methods}

The methods assessed are; intention to treat (ITT), perprotocol (PP), adjusted Cox model [1], causal proportional hazards estimator [2], rank-preserving structural failure-time models (RPSFT) [3], iterative parameter estimation (IPE) [4], parametric randomisation based method [5], and the less well known inverse probability of treatment weighting (IPTW) [6].

\section{Data}

Survival data having an underlying Weibull distribution was simulated and designed such that probability of switching for patient subgroups could be varied within treatment-arms. Other subgroup characteristics could be controlled and 24 scenarios with varied levels of bias were analysed. A review of submissions to the National Institute of Clinical Excellence was performed and used to inform the scenario parameters.

\section{Results}

The RPSFT and IPE methods returned the lowest biases, $<8 \%$, in all scenarios. The estimates of the parametric randomisation based method were often far less variable than other methods but were subject to erratic behaviour with extreme biases observed. The other methods

${ }^{1}$ Cancer Research UK Clinical Trials Unit, University of Birmingham, Birmingham, B15 2TT, UK

Full list of author information is available at the end of the article

performed poorly in general, with biases of up to $50 \%$ not uncommon. In particular the IPTW method overcompensates in most scenarios.

\section{Conclusion}

Under these conditions the results clearly identified the RPSFT and IPE methods as most consistent and accurate, with the latter the more consistent of the two. None of the other methods returned consistent results, and as such cannot be recommended.

Further avenues of investigation include exploring the effect of other underlying survival distributions, extending from univariate models to adjust for other covariates, and extending from situations where just controlarm patients switch to scenarios with multidirectional cross-over.

\section{Author details}

${ }^{1}$ Cancer Research UK Clinical Trials Unit, University of Birmingham, Birmingham, B15 2TT, UK. ${ }^{2}$ MRC Midland Hub for Trials Methodology Research, University of Birmingham, Birmingham, B15 2TT, UK. ${ }^{3}$ Centre for Biostatistics and Genetic Epidemiology, University of Leicester, Leicester LE1 6TP, UK.

\section{Published: 13 December 2011}

\section{References}

1. Law, Kaldor J: Survival analyses of randomised clinical trials adjusted for patients who switch treatment. Stat Med 1996, 15:2069-2076.

2. Loeys T, Goetghebeur E: A causal proportional hazards estimator for the effect of treatment actually received in a randomised trial with all-ornothing compliance. Biometrics 2003, 59(1):100-105.

3. Robins J, Tsiatis A: Correcting for non-compliance in randomised trials using rank preserving structural failure time models. Communication in Statistics-Theory and Methods 1991, 20(8):2609-2631.

4. Branson $M$, Whitehead J: Estimating a treatment effect in survival studies in which patients switch treatment. Stat Med 2002, 21:2449-2463.

5. Walker S, White I, Babiker A: Parametric randomization-based methods for correcting for treatment changes in the assessment of the causal effect of treatment. Stat Med 2004, 23:571-590. (c) 2011 Fox et al; licensee BioMed Central Ltd. This is an open access article distributed under the terms of the Creative Commons Attribution License (http://creativecommons.org/licenses/by/2.0), which permits unrestricted use, distribution, and reproduction in any medium, provided the original work is properly cited. 
6. Hernan M, Brumback B, Robins J: Marginal structural models to estimate the causal effect of zidovudine on the survival of HIV-positive men. Epidemiology 2000, 11(5):561-570.

doi:10.1186/1745-6215-12-S1-A139

Cite this article as: Fox et al: Evaluation of methods to adjust for treatment switching in clinical trials. Trials 2011 12(Suppl 1):A139.

Submit your next manuscript to BioMed Central and take full advantage of:

- Convenient online submission

- Thorough peer review

- No space constraints or color figure charges

- Immediate publication on acceptance

- Inclusion in PubMed, CAS, Scopus and Google Scholar

- Research which is freely available for redistribution

Submit your manuscript at www.biomedcentral.com/submit

() BioMed Central 